\section{Developing biologists}

The Developmental Biology of Plants and Animals, edited by C. F. Graham and P. F. Wareing (Blackwell Scientific: Oxford and London, £7.75: Saunders: Philadelphia), is unusually courageous for a textbook in treating development as a biological problem. not simply as zoology or botany. This approach has clear gains (for example. cell interactions and control of differentiation) but also losses: a selection of topics that "have a bearing on general themes of plant and animal development" (my italics) inevitably excludes many of relevance to only one or the other. On the animal side, the book has nothing on extraembryonic membranes and, more seriously, next to nothing on cell movements.

The book is in six parts, most with an introductory chapter and short conclusion by the editors. Individual chapters are by 20 different authors. mainly writing from British laboratories (except J. T. Bonner from the USA). Integration is achieved by extensive cross-referencing. Figures are used sparingly, giving us a lot of text for our money. The book is advanced, not introductory: most chapters assume basic hackground. and some use an eclectic range of examples and terminology that would soon baffle a beginner.

In a book of this scope an individual is bound to have both praise and grumbles over facts or emphasis. Many chapters seem to me admirable critical summaries of our present knowledge- those on animal cell junctions and the control of gene expression are especially clear. On the other hand, the emphasis of the chapter on "selfassembly" seems misplaced. There is lots of physical chemistry', but very little on regulation. surely the central issue for developmental biologists. "Pattern formation in animal embryos" is not for the unwary, reading simply for information: it suggests short range inductions rather than gradients or positional information as the hasic mechanism-a stimulating article, belonging more in a journal than a textbook. The section on environmental effects (rarely mentioned in accounts of animal development) disappoints me. Although most work has been on model animals in laboratories, emphasising the constancy of devclopmental processes, information is now appearing on ecological factors (for example, on the timing of amphibian metamorphosis), but none of this is mentioned.

Some small points: a student ignorant of Ascaris might get the impression that chromosome diminution never occurs (p302). Is vertebrate limb elongation "entirely due to addition of tissue at the tip" (p180)? Why no mention of Roth's (1973) hypothesis as a mechanism of cell interactions (chapter 3.1)? And two irritations: tubulin repeatedly spelt tubullin (p259): reference lists at the end of each chapter, some in alphabetical order. others not, rather than altogether at the end.

Do advanced students need a textbook? Many courses prefer directed reading in the original literature and reviews, since ageing is rapid in the subjects covered here. Although the cover date is 1976, the book's literature survey just scrapes into 1974, comparing unfavourably with its most direct competitor, Lash and Whittaker's Concepts of Development (Sinauer : Stamford. 1974), almost as up-to-date, despite its earlier publication. The incompleteness makes the book less than ideal for either botanical or zoological courses) still in the majority?). Students

\section{Recipe books for crop production}

Crop Production: Principles and Practices by S. R. Chapman and I... P. Carter (Freeman: San Francisco, \$15) is one of several similar books that outline the production of crops in the United States. All of them profess to introduce the principles of crop production before detailing the growing procedure for the major crops. For example, in this book by Chapman and Carter... "Our philosophy has been that modern highly productive farming practices depend on an understanding of the principles of plant growth. When the principles are grasped, the practices follow logically." This is a commendable philosophy for the teaching of undergraduates in agriculture. but when a closer look is taken at these introduction principles (approximately half of the hook) we find. in spite of a beautifully illustrated text, a rather thin veneer of elementary botany covering once again mitosis and meiosis, simple plant morphology. properties of soils, and so on which seem too common an occurrence in so many agricultural texthooks that try to cover too much matcrial. To give two examples, where are the principles relating economic crop yicld to plant density, which can explain seeding rate and crop establishment practices: and where are the principles of fertiliser response curves on which all fertiliser recommendations need to be based? may simply regard the 'irrelevant' chapters as money down the drain.

Despite these general doubts, and a few grumbles about details, I'd still heartily recommend this book for the excellence of many of its chapters, for its thoughtful overall philosophy, and for those sections which include examples from both kingdoms-they'll make biologists of us yet!

I cannot so easily recommend John McKenzie's Introduction to Developmental Biology (Blackwell Scientific: Oxford and I.ondon, £4.25: Halsted/ Wiley: New York). This takes the view that students need to be cajoled into an interest in development by examining human development first. This may be true of medical students, but not, in my experience, of biologists. For an introduction, the book has too many unexplained anatomical terms (no glossary) and minor errors.

J. R. Downie

I. R. Downie is Lecturer in Zoology at the University of Glasgow, UK.

As our present knowledge of field crop physiology gives a clearer understanding of many' common crop practices throughout the world, it should now form the basis of crop production textbooks.

The second half of the book deals with production practices for each crop in the form of a growers' manual. This may be a useful source of reference, but one hopes that present undergraduates are not expected to learn and inwardly digest the factual details of crop-growing procedures. A further indication of thin coverage, is the allocation of only six pages of text to the maize crop, particularly since the crop originates from a country that produces $40 \%$ of the world's production.

In contrast, the latest edition of Principles of Field (rop Production (Collier-Macmillan: L.ondon, £7) by Martin, Leonard and Stamp gives some five times this coverage and would provide a better reference source. But in the final analysis, the recipe book approach to crop production makes this type of texthook no more effective than a farmer's manual for the country of origin. How. for example, does a University level agronomist. who has been reared on such a diet. adapt to unfamiliar environments, such as the third world, without an understanding of the principles of field crop growth?

G. M. Milbourn

G. M. Milbourn is Senior Lecturer in Crop Production at Wye College. University of London, UK. 